\title{
SOBRE EL MÉTODO DE LA INTERPRETACIÓN DOCUMENTAL Y EL USO DE LAS IMÁGENES EN LA SOCIOLOGÍA: Karl Mannheim, Aby Warburg y Pierre Bourdieu ${ }^{1}$
}

\author{
Amalia Barboza Martínez*
}

Resumen: El método de interpretación documental elaborado por el sociólogo Karl Mannheim ofrece herramientas de análisis indicadas para integrar materiales visuales en las investigaciones sociológicas. Esto se debe a que Mannheim elaboró este método basándose en los avances metodológicos de los historiadores del arte de su época. En este artículo se presenta en un primer apartado las características centrales de este método. En una segunda parte se muestra que existe dos formas de aplicación de este método a la hora de hacer uso de las imágenes. Por un lado las imágenes pueden ser objeto del método documental. Por otro lado la producción de imágenes pueden servir como técnica para realizar un análisis documental de la sociedad.

Palavras-clave: método de interpretación documental, Mannheim, materiales visuales, sociología, Warburg, Bourdieu.

Dentro del marco de la sociología son escasos los trabajos en los que se haya hecho uso de la imagen visual. En su artículo "The Early History of Visual Sociology", sugiere Clarice Stasz (1979) que una de las razones de esta exclusión se debe al camino que tuvo que seguir la sociología en sus comienzos para poder constituirse como disciplina científica. La sociología se vio obligada a la especialización

\footnotetext{
* Doutora em Sociologia pela Universidade Técnica de Dresden, docente na Universidade de Frankfurt am Main.E-mail: amaliabarboza@composerve.de

Artigo recebido em 10 out. 2005; aprovado em 24 abr. 2006.
} 
y consecuentemente a la delimitación de sus contornos, apartando todo aquello que no hiciese de ella una ciencia exacta. Tanto la utilización de imágenes como también el uso de un estilo literario hacían de la sociología una disciplina que difícilmente podía elevarse a aquello que se definió como "ciencia". Estos elementos visuales y literarios ligan a la sociología al género periodístico, al campo artístico o a la literatura. Para poder establecerse como "ciencia" se vieron los sociólogos ante la situación de tener que librarse de estos aspectos y elaborar métodos que estuviesen mas ligados al conocimiento de las ciencias exactas. Los métodos cuantitativos, las estadísticas y encuestas ofrecían la posibilidad de exponer datos cuantificables de la sociedad. De esta forma se fueron dejando de lado todo aquel material, documento y método que no aportase un conocimiento cuantificable. Siguiendo este argumento muestra Stasz cómo en el American Journal of Sociology desaparecen a partir del año 1916 los estudios ilustrados que se venían publicando desde 1896. A partir de 1916 las gráficas de datos estadísticos van desplazando a las imágenes.

Esta exclusión de materiales visuales de la sociología ha hecho que los métodos utilizados por sociólogos no se hicieran adecuados para el análisis y la utilización de imágenes. El sociólogo que hoy en día se planteé la utilización de imágenes en sus investigaciones se verá ante el problema de tener que establecer un método apropiado para el análisis y para el uso de este material visual.

En este artículo me propongo presentar el método de interpretación documental del sociólogo Karl Mannheim como un modelo ejemplar para hacer uso de la imagen en la sociología. La adecuación del método de Mannheim al análisis de imágenes se debe a que éste elaboró su método de interpretación de fenómenos culturales basándose en los avances metodológicos de la historia del arte, un campo en el que los documentos visuales son el centro de interés del investigador. Mannheim utilizó en sus escritos de sociología de la cultura y del conocimiento determinados conceptos, como el concepto de "estilo" o el concepto "voluntad de forma" - "Kunstwollen" - (Riegl, 1992), que provienen del campo de la 
historia y de la teoría del arte. Esta relación de la sociología de Mannheim con la historia del arte ha sido escasamente estudiada. ${ }^{2}$ Es sabido que el historiador Erwin Panofsky $(1992,1978)$ desarrolló en los años treinta su método de la iconología basándose en el método de interpretación documental. ${ }^{3}$ Menos conocido es que Mannheim (1923) a su vez, para elaborar un método para la sociología de la cultura, se basó en las discusiones metodológicas de algunos historiadores del arte, como por ejemplo Alois Riegl, Max Dvořák o el mismo Erwin Panofsky.

Gracias a esta proximidad del método de interpretación documental de Mannheim a la disciplina de la historia y la teoría del arte es que este método ofrece un modelo ideal para el análisis de imágenes en la sociología. Por otro lado, como expondré más adelante, el método de la interpretación documental no sólo nos ofrece una técnica de análisis de la imagen, sino que a la vez constituye un método que está predestinado a hacer uso de la imagen, esta vez no como objeto de estudio, sino como técnica de análisis sociológico.

En la primera parte de este texto presentaré de forma resumida el método de interpretación documental para después en la segunda parte referirme a dos posibles formas de utilización de las imágenes valiéndose de este método.

\section{Aspectos centrales del método de la interpretación documental}

Para entender la singularidad del método de interpretación documental es útil ver cómo éste se diferencia de otros métodos de análisis. En sus primeros escritos sobre la sociología de la cultura Mannheim diferencia entre las diversas perspectivas a la hora de analizar obras de arte. ${ }^{4}$ Por un lado se puede utilizar un método que analice la obra de arte de forma inmanente. Este análisis inmanente es normalmente utilizado en el campo de la estética. El método inmanente consiste en describir los aspectos estéticos formales de una obra o bien en un análisis de los temas y contenidos explícitos 
en la obra. Otra perspectiva de análisis ofrece el método genético. Mientras el método inmanente analiza las características estéticas y temáticas presentes en la obra, no se trata en el método genético de estudiar la obra en sí, sino más bien de analizar el contexto social e histórico en que la obra fue realizada. Este método consiste en analizar la génesis social de las obras de arte: aquellos acontecimientos que hicieron posible su aparición.

Normalmente se considera el método genético como el método de la sociología. El sociólogo no trata discusiones estéticas, sino que analiza las condiciones sociales del surgimiento de una corriente artística o de una obra de arte.

En sus escritos sobra la sociología de la cultura expone Mannheim estos dos métodos, el método inmanente y el método genético, como las dos alternativas más comunes a la hora de analizar obras de arte. La tarea que él se plantea para su sociología de la cultura es la de dar con un método que una estas dos alternativas. La sociología de la cultura pretende analizar las obras de arte, no se contenta con un método que sólo considere los acontecimientos exteriores a la obra. Ahora bien, este análisis de la obra no ha de ser inmanente, ya que no es la tarea del sociólogo el mero análisis de las características estéticas y de los significados inmediatos expresados por la obra. El interés del sociólogo se dirige a la información social que está presente en las imágenes. El sociólogo de la cultura, siguiendo la propuesta de Mannheim, debe analizar una obra de arte descubriendo en ella la expresión de una postura ante el mundo característica de la posición social del artista, de la época o del momento social e histórico en la que la obra fue realizada. Mannheim encuentra la síntesis entre el método inmanente y el método genético en el método que él denomina interpretación documental.

En su escrito "Contribuciones a la interpretación de la visión del mundo", ${ }^{5}$ Mannheim (1923) diferencia entre tres niveles de sentido para poder definir nivel del sentido documental. En el primer nivel la imagen aparece como representación de un estado de cosas o de una situación, siendo requisitos necesarios para que podamos captar 
este primer sentido el que poseamos ciertas experiencias cotidianas para reconocer determinados objetos y tengamos familiaridad con los principios estilísticos de representación adoptados por el artista. Gracias a estos conocimientos previos podemos reconocer en una imagen la representación de una figura volando o de una aparición celestial. Este primer nivel es bautizado por Mannheim como sentido objetivo. Un segundo nivel se refiere al contenido expresivo que el realizador de la imagen presumiblemente intenta manifestar a través de la realización de su obra. A este segundo nivel lo nombra Mannheim sentido expresivo. La interpretación de un fenómeno cultural no se interrumpe cuando identificamos su sentido objetivo y comprendemos la intención del sujeto, sino que puede proseguir en un tercer nivel de sentido: se puede desvelar en una imagen los principios fundamentales de una postura hacia la realidad sobre los cuales ella reposa, pasando este fenómeno a ser comprendido, de esta manera, como manifestación o documento de una determinada concepción del mundo. En este plano no nos ocupamos más con lo que el artista quería expresar, sino con la visión del mundo que se manifiesta en su obra. Este sentido, en principio oculto, consistiría, de acuerdo con Mannheim, en el sentido esencial de los fenómenos culturales y es caracterizado como sentido documental.

En este tercer nivel de interpretación no nos referimos a acontecimientos externos a la obra, sino que a través de la obra damos con la concepción del mundo que en ésta se manifiesta. Este tercer nivel de interpretación es el método que Mannheim considera indicado para un análisis sociológico de la cultura.

Siguiendo el método de Mannheim el historiador del arte Erwin Panofsky $(1992,1978)$ elaboró un método parecido que también discurre en tres niveles de interpretación. La teoría de Panofsky varía en algunos aspectos del modelo original de Mannheim. El primer nivel de interpretación, que en Panofsky es bautizado como nivel preiconográfico, y el tercer nivel de la interpretación documental, que en Panofsky constituye el nivel iconológico, concuerdan con el modelo de Mannheim. Sólo en el segundo nivel de interpretación se diferencian los dos modelos: Mannheim se refiere a la intención del 
autor y Panofsky se refiere en su segundo nivel de interpretación, el nivel iconográfico, al conocimiento literario que es transmitido a través de la obra. Este conocimiento literario nos permite por ejemplo entender que la imagen de un grupo de personas comiendo representa la última cena.

El tercer nivel de interpretación, el método de interpretación documental y el método iconológico, ofrece una perspectiva de análisis de imágenes que se diferencia claramente de los otros niveles de sentido. En el tercer nivel no se trata de dar con el sentido objetivo, con lo que en un principio la imagen representa; tampoco de descubrir la intención del autor (sentido expresivo) o el tema mitológico representado (sentido iconográfico), sino de entender la imagen como documento de una actitud emocional peculiar al período o a la sociedad en la que fue producida. El investigador que haga uso de este método tendrá la tarea de elevar aquellos trazos y aspectos característicos de una obra que traigan a relucir de forma evidente la singularidad de un grupo social o de una época determinada. Erwin Panofsky, por ejemplo, ha mostrado cómo las representaciones de las proporciones del cuerpo humano en diferentes épocas y culturas pueden ser estudiadas como documentos singulares de las diferentes concepciones del mundo. ${ }^{6}$ En otro trabajo ha analizado Panofsky los sistemas de perspectiva utilizados en varias épocas y culturas, ya que en estos sistemas se hace patente las diferentes formas de percepción y concepciones del mundo. La interpretación documental o iconológica muestra como en estas diferencias de composición del espacio o de técnicas de representación del cuerpo se pueden extraer claros documentos de la concepción del mundo de las diferentes épocas.

Este método, que ha tenido su mayor repercusión en el campo del arte, puede ser igualmente utilizado para el análisis de situaciones sociales o de otros fenómenos culturales que no tienen por que ser expresados de forma visual. Mannheim, por ejemplo, que se planteó la aplicación de este método en la sociología de la cultura para el análisis de todo fenómeno cultural, realizó sus análisis concretos no en el campo de la producción de imágenes o en 
el campo de las obras de arte, sino en el campo de la producción de conocimiento. En sus trabajos de sociología del conocimiento analiza Mannheim $(1984,1995)$ los diferentes estilos de pensamiento. ${ }^{7} \mathrm{La}$ tarea consiste en analizar las diferentes formas de pensar como también los diferentes temas y conceptos utilizados por distintos pensadores. En este análisis descubre Mannheim la existencia de claras diferencias estilísticas. Estas diferencias no son tratadas de forma inmanente. Es decir, Mannheim no realiza solamente un análisis de las formas de pensar o de los conceptos e ideas de cada estilo de pensamiento. Este nivel de análisis es superado por el tercer nivel de la interpretación documental: Las diferencias formales y de contenido entre pensadores son interpretadas como diferencias que sacan a relucir las concepciones del mundo de cada pensador.

Es de señalar que en esta aplicación del método documental a otros campos culturales, como el del conocimiento, el análisis discurre como si se tratara de un análisis de imágenes. Mannheim descubre por ejemplo entre diferentes pensadores o bien una tendencia a la abstracción o bien una tendencia a lo concreto, así también una tendencia a la exposición sistemática formal o una tendencia a una exposición dinámica. Estas diferencias de estilo en el campo del conocimiento pueden igualmente aparecer al analizar imágenes y obras de arte.

La ampliación del método documental a otros campos supone un aspecto central del método documental. Mostrar paralelismos de estilo entre diferentes campos culturales constituye para Mannheim la tarea central del sociólogo de la cultura. El sociólogo del conocimiento o el sociólogo del arte pueden limitar el análisis documental a un campo de estudio. El sociólogo de la cultura tiene en cambio la labor de analizar varios campos culturales, para en todos ellos dar con el mismo sentido documental. La tarea consiste en establecer semejanzas de estilo entre diferentes esferas culturales, para así descubrir la concepción del mundo que emana de todas ellas. Mannheim retoma el concepto de "equivalencia" (Entsprechung) del historiador del arte Max Dvořák para definir esta ampliación del método documental a varios campos culturales. Se trata de mostrar 
las tendencias equivalentes entre fenómenos culturales de una misma época o de un mismo grupo social.

El método de la sociología de la cultura consiste pues en una extensión del método documental a varias esferas culturales. Este método tiende a un trabajo interdisciplinar, ya que el investigador tratará de analizar varios fenómenos, para encontrar las tendencias características comunes.

La aplicación de un método interdisciplinar se siguió de una forma ejemplar en el centro de investigación del historiador del arte Aby Warburg, donde Erwin Panofky encontró un lugar ideal para llevar a la práctica el método iconológico. Antes de Panofsky Aby Warburg había utilizado la definición "iconología" para referirse a un estudio interdisciplinar en donde la historia del arte no estuviese restringida a un análisis puramente formal de las obras de arte. La iconología, como Panofsky expone en sus escritos teóricos, tiene el objetivo no sólo de analizar el sentido documental de una obra sino también de comparar lo que el investigador cree que es el significado documental de la obra con el significado documental de otros documentos que testifiquen sobre las tendencias políticas, poéticas, religiosas, filosóficas y sociales de la personalidad, período, país o grupo social que esté investigando (Panofsky, 1978, p. 48). En la búsqueda del significado documental es donde las diferentes disciplinas se encuentran unidas en una investigación común. Panofsky, que se dedicó a la sistematización teórica de este método, encontró la posibilidad de su aplicación en el instituto Warburg. La biblioteca del instituto Warburg fue concebida para este tipo de investigación interdisciplinar. Warburg dedicó toda su vida al estudio de la concepción del mundo de la antigüedad clásica y de su vigencia en la cultura occidental a lo largo del tiempo. Para esta investigación se recopiló en la biblioteca del instituto todo tipo de publicaciones dedicadas el estudio de cualquier fenómeno de la antigüedad clásica y de su desarrollo a lo largo de las épocas. La investigación, y con ello la recopilación de libros, abarca, en el plano horizontal, todos los fenómenos culturales posibles, y, en el plano vertical, todas las épocas en donde se recogen rastros de la tradición 
clásica. La biblioteca fue organizada de tal forma que permitiese establecer semejanzas entre los diferentes campos disciplinares para así mostrar la relevancia de esta tradición en todos estos campos.

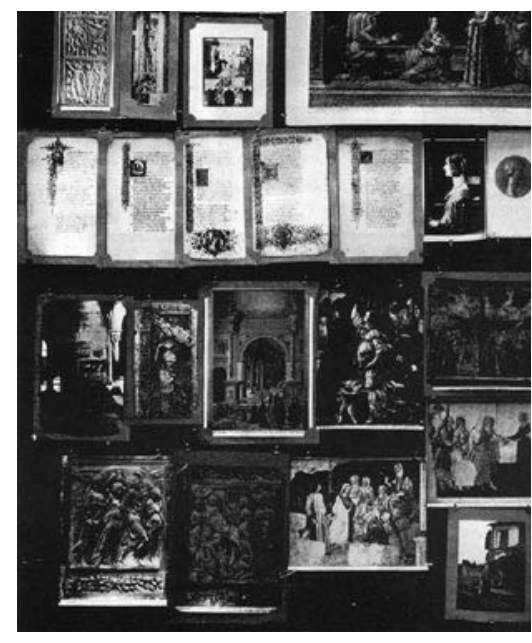

Mnemosyne: Lámina 1:

"Macrocosmos y Microcosmos"

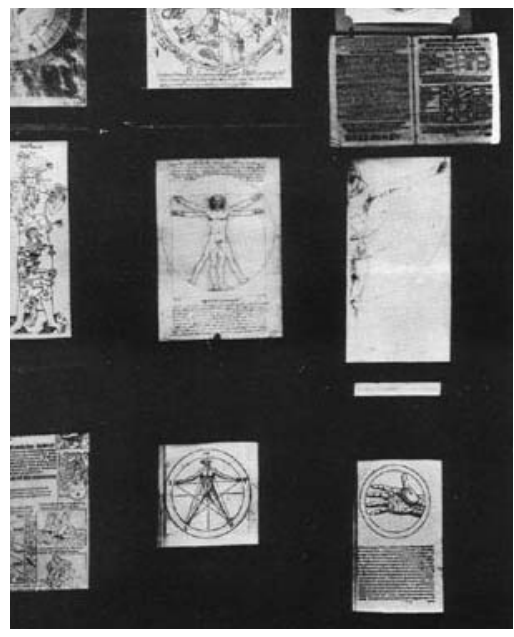

Lámina 2:

"La Ninfa". En: Gombrich (1992)

Por otro lado, y de gran importancia para el uso de la imagen en la investigación, Warburg desarrolló un método en el que la imagen actúa como documento central para investigar las tendencias características de una cultura. ${ }^{8}$ Warburg denominó este proyecto el Atlas Mnemosyne, un Atlas de la memoria visual. Sobre todo en las expresiones corporales, documentadas por medio de imágenes a lo largo de los siglos, Warburg quiso mostrar cómo la cultura occidental guarda una memoria cultural que sigue vigente. Con este objetivo se exponían los resultados de la investigación a través de una técnica visual, organizando las fotografías en unas pantallas de fondo negro (Gombrich, 1992).

El proyecto Mnemosyne no solamente se constituía de una colección de reproducciones de obras de arte, sino también de reproducciones fotográficas de todo tipo de imágenes, como 
anuncios publicitarios, sellos o estampas. Para esta búsqueda de imágenes existía en el instituto Warburg un laboratorio fotográfico y un fotógrafo plenamente dedicado a las investigaciones del instituto. De estas forma logró Warburg ampliar el campo de trabajo del historiador a todo documento visual posible.

Antes concluir con este primer apartado quisiera, recapitulando, definir el método documental enumerando sus principales características:

1) se trata de un método de análisis de imágenes como también de otros fenómenos culturales, en donde se analizan los aspectos tanto formales como de contenido característicos del objeto de estudio sin limitarse a un análisis inmanente, sino que analizando la concepción del mundo que se expresa a través de estos aspectos resaltados;

2) por otro lado el método documental supone también la ampliación del análisis documental a varios fenómenos culturales. El análisis no se acota a un campo sino que por el contrario hace ver que en las diferentes esferas culturales de una época, de una generación o de grupo social, se expresa un estilo común a todas ellas. Es por eso que el método documental no solamente supone la superación de un análisis formal e inmanente, sino también la superación de un análisis autónomo y especializado, tendiendo a promover un análisis interdisciplinar.

\section{Las diferentes funciones de la imagen en la interpretación documental}

Si bien existen varias formas de aplicación de las imágenes a las investigaciones, se puede diferenciar principalmente entre dos tipos. Por un lado una imagen puede ser vista como objeto de estudio, es decir como documento de la concepción del mundo del productor o productores de la imagen. Por otro lado se puede concebir la producción de imágenes como técnica de documentación 
de los aspectos peculiares de una sociedad. En este apartado voy a referirme a estos dos tipos de aplicación dando algunos ejemplos de investigaciones en donde se ha hecho uso de documentos visuales. Hay que aclarar que se trata de tipos, que bien pueden y suelen darse de forma complementaria en una investigación.

\section{Imagen como objeto de estudio}

En la historia del arte el uso corriente del método de la interpretación documental se basa en un análisis de las imágenes para a través de éstas estudiar la concepción del mundo del artista. Siguiendo esta perspectiva el investigador centra su análisis en los aspectos característicos de una obra de arte, como puede ser la técnica aplicada, la forma de representación, el tipo de composición, los temas representados, para descubrir en estos aspectos documentos claves de la concepción del mundo de una época, de un grupo social o de una generación determinada. El investigador resalta aquello que por un lado caracteriza la obra y que por otro expresa la concepción del mundo del productor. En este sentido un determinado cuadro en donde el artista utiliza una pincelada corta de distintos colores yuxtapuestos se suele en la historia del arte catalogar como un cuadro impresionista. Esta característica estética expresa a la vez una determinada postura del artista. En este sentido el estilo impresionista ha sido considerado como un documento de la excitación visual del hombre moderno.

Más allá del ámbito de la historia del arte, desde una perspectiva de las ciencias de la cultura como se mostró en el instituto Warburg, se ha hecho uso no sólo de obras de arte, sino de todo tipo de documento visual para estudiar una determinada cultura. También en el campo de la sociología de la cultura encontramos estudios donde tanto imágenes, como objetos, espacios y monumentos son analizados como documentos de una época. El sociólogo Georg Simmel por ejemplo, si bien en sus ensayos no incluye la reproducción de materiales visuales, hace referencia constante al mundo visual de 
la sociedad moderna. Simmel indaga en el significado documental de fenómenos como las exposiciones de arte, la moda, las grandes ciudades, el dinero o el marco de las obras de arte. ${ }^{9}$ En su libro La filosofía del dinero (Simmel, 1996) están reunidos varios de sus análisis con el objetivo de hacer ver cómo algunos fenómenos como la moda y el dinero se encuentran intrínsicamente relacionados, ya que ambos son documentos centrales de la concepción del mundo de la modernidad.

Una perspectiva semejante a la del método documental la encontramos también en el proyecto de los Pasajes, proyecto inacabado del sociólogo Walter Benjamín, donde los pasajes comerciales de las ciudades principales de Europa son analizados como documentos centrales de la sociedad capitalista (Buck-Morss, 1995). Benjamin no sólo analizó los espacios de las ciudades de Paris, Berlín y Nápoles, sino que también se dedicó al estudio del movimiento de las personas en las ciudades, al estudio de las mercancías, de imágenes publicitarias, etc. Desgraciadamente solamente han quedado una colección de notas. Notas que se refieren a documentos de todo tipo que fueron archivados con un mínimo de comentarios, para después ser ordenados como si se tratase de un retrato sobre la industria cultural del siglo XIX.

En estos dos autores, Georg Simmel y Walter Benjamin, encontramos la aplicación del método documental en su ampliación a todos los campos de la cultura visual posibles, como corresponde a la sociología de la cultura. Ya no son sólo las obras de los artistas, sino toda la producción de una sociedad pasa a ser objeto de estudio. Se podría decir que el método de interpretación documental consiste en ampliar el campo de estudio del campo del arte a toda la cultura visual.

Común a todos estos ejemplos es el análisis de materiales visuales ya existentes. Una variante posible dentro de esta perspectiva supone el planificar en la investigación la producción de los datos que van a ser objeto de estudio. En una investigación de los antropólogos Sol Worth y John Adair (1972) sobre la concepción del mundo de 
los indios navajos se propuso justamente la producción de material visual. ${ }^{10}$

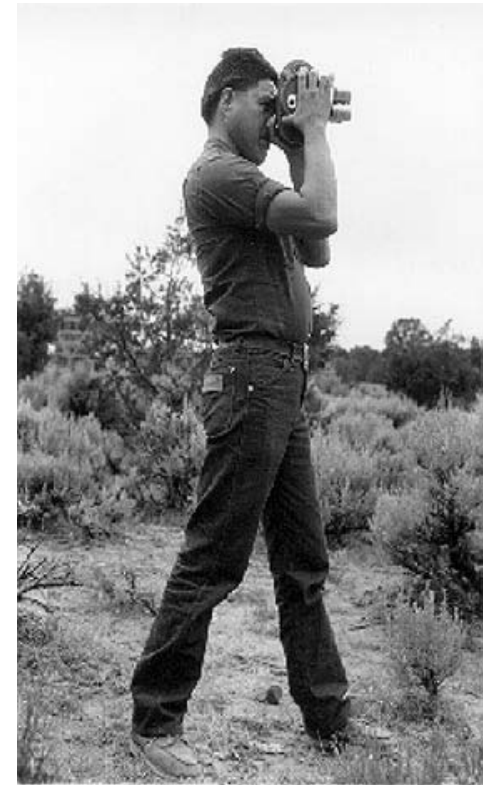

Foto 1: Johnny Nelson, shooting "Navajo Silversmith", Pine Springs, Arizona., July, 1966, photo by Dick Chalfen. En: http://astro.temple. edu/ rchalfen/navajo.html

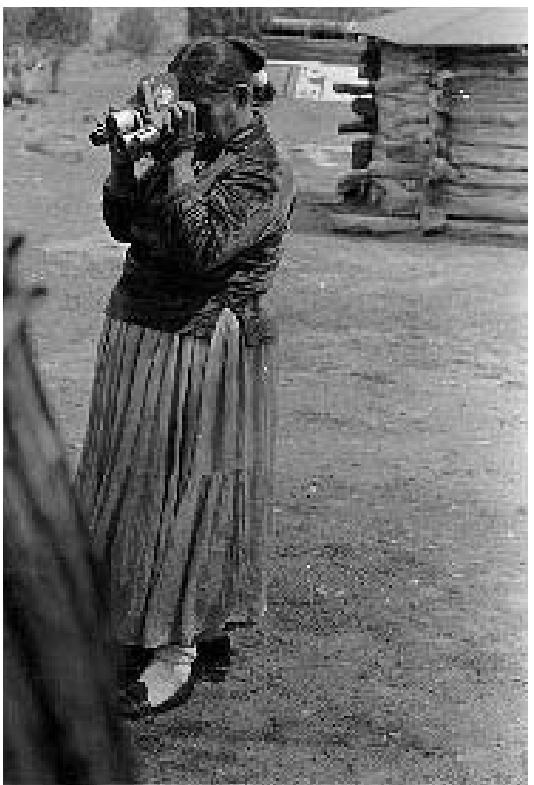

Foto 2: Alta Kahn shooting "Navajo Weaver II", Pine Springs, Arizona, July, 1966, photo by Dick Chalfen. En: http://astro.temple.edu/ rchalfen/ navajo.html

En esta investigación se incentivó a las personas objeto de estudio a que durante un tiempo realizasen fotos, para después poder hacer uso de estas fotografías como documentos de su forma específica de ver el mundo. En la investigación de Sol Worth y John Adair se utilizaron cámaras de video para que los indios navajos filmasen temas de su vida cotidiana. La forma de filmar, los temas y enfoques elegidos trajeron a la luz la peculiar forma de percibir el entorno de esta comunidad. Más adelante, en una comparación de estas filmaciones con las realizadas por americanos blancos, se pudieron reconocer diferencias significativas sobre la percepción del espacio y el tiempo de los indios navajos. 
A parte de esta planificación de la creación de material visual a ser investigado tuvo en esta investigación la producción de material visual un papel central. Sol Worth y John Adair se propusieron constituir una antropología visual que no sólo tome como objeto de estudio materiales visuales, sino que también incluya la documentación fotográfica en la investigación. Sol Worth y John Adair realizaron una documentación fotográfica del espacio y las costumbres de los indios navajo. Este tipo de documentación fotográfica nos lleva a otra forma de utilización de la imagen distinto del hasta ahora expuesto. La imagen ya no es utilizada para ser analizada como documento de la concepción del mundo del productor o productores de la imagen, sino que la imagen le sirve ahora al investigador como técnica de documentación y presentación de aquellas situaciones y aspectos de una sociedad que resulten documentos ejemplares de ésta.

\section{La imagen como técnica de análisis}

Normalmente el sociólogo estudia una sociedad realizando entrevistas, grupos de discusión o descripciones de sus experiencias que son llevadas al papel, si bien muchos de los datos de lainvestigación se basan en experiencias visuales. En estas observaciones del mundo visual el investigador tiene que realizar una especie de traducción para pasar los datos visuales a la descripción escrita, dejando muchos elementos de lado que difícilmente se pueden exponer en un texto. Esta labor de traducción la encontramos por ejemplo en el proyecto de los Pasajes de Walter Benjamín. Para este proyecto Benjamin utilizó un método de análisis de la sociedad basado principalmente en experiencias visuales: El método de los Pasajes consistió en utilizar una "experiencia sensorial" que se asemeja a la experiencia de alguien que camina por las calles de una ciudad. ${ }^{11}$ El caminante recoge a lo largo del paseo una cantidad de imágenes sobre esta ciudad, como si fuese documentando su paseo a través de la cámara. No consta que Benjamin hiciera uso de la fotografía, pero muchas de las escenas que él describe se parecen a descripciones 
de secuencias fotográficas, que recogen el comportamiento de las personas en la ciudad. Es sabido que para el proyecto de los Pasajes Benjamin fue recolectando imágenes en sus paseos, en archivos y que incluso fue coleccionando objetos durantes todos sus viajes. Como explica Susan Buck-Morss (1995), que se propuso reconstruir el proyecto inacabado de Benjamín buscando las imágenes a las que se refiere Benjamín en sus notas, ${ }^{12}$ supone esta colección de imágenes el resultado central de la investigación. No sólo los ensayos y observaciones, sino justamente estos materiales visuales conforman la investigación de Benjamin sobre la cultura urbana del siglo XIX y comienzos del siglo XX.

Está documentación visual supone en sí una interpretación documental, pues el investigador no sólo elige el enfoque y la perspectiva adecuada, sino que también selecciona aquellas imágenes y secuencias que a él le parecen más representativas para exponer lo específico de su objeto de estudio. Esta selección es el producto de una interpretación documental, que tal vez funcione de forma inconsciente, pero que sigue el principio fundamental característico de este método: el resaltar aquellos elementos que documentan lo específico de un grupo social.

Este uso de la imagen es el que se ha venido utilizando sobre todo en informes fotográficos o en películas documentales. Pero también ha habido dentro de las disciplinas académicas proyectos para integrar la producción visual a las investigaciones.

Un ejemplo de la utilización de fotografías en la investigación social fue el proyecto de la Farm Security Administration (FSA) llevado a cabo en los años veinte en Estados Unidos en donde trabajaron fotógrafos y científicos sociales juntos. ${ }^{13}$ En esta investigación se incluyó como método central de análisis la producción de fotografías. Éstas fueron realizadas por fotógrafos que recibían indicaciones de un grupo de científicos, como por ejemplo una lista de temas para organizar el reportaje fotográfico. En 1942 se le encargó a Paul Vanderbilt la organización y el archivo de las más de cien mil fotografías de la FSA. Vanderbilt propuso una organización de las fotografías, pero su trabajo no llevó a una 
presentación oficial de las fotografías como resultado final de la investigación.

La integración de las imágenes en la presentación de los resultados de investigaciones ha sido y sigue siendo hoy en día un problema para el investigador, ya que éste se ve ante la situación de tener que ir más allá de las formas tradicionales de presentación dentro del campo de la producción científica. El sociólogo Pierre Bourdieu acata esta reserva de los científicos sociales a una "censura del pudor científico" (Bourdieu, 2003, p. 47). Él mismo se vio objeto de esta autocensura a lo lago de su experiencia como sociólogo. Pues si bien Bourdieu realizó innumerables fotografías en sus investigaciones, nunca se permitió la inclusión de éste material. Sobre todo en sus primeras investigaciones sobre la sociedad argelina fue para Bourdieu la práctica de la documentación fotográfica un método imprescindible de análisis. Durante su estancia en Argelia realizó Bourdieu más de 3.000 fotografías. Retrospectivamente considera Bourdieu que él mismo se censuró la presentación de estos resultados visuales como también de otros resultados literarios a causa de "la preocupación de no llegar a ser lo suficientemente científico" (Bourdieu, 2003, p. 48).

En los últimos años de su vida se propuso Bourdieu la recopilación de este material visual junto con la ayuda de la revista de fotografía Camara Austria. Este trabajo visual, que ha sido publicado póstumamente,${ }^{14}$ nos muestra que Bourdieu hizo uso de la producción fotográfica de una forma sistemática, siguiendo proyectos concretos. Uno de los proyectos de análisis visual fue el estudio de lo que Bourdieu llamó la "economía de la miseria" (p. 41), es decir, de los espacios y mecanismos que los hombres inventan para sobrevivir, como por ejemplo la creación de formas transportables de comercio (foto 1). Muchas de las fotografías pertenecen a esta serie sobre comercios transportables.

Otros de los temas de análisis visual de Bourdieu consistió en buscar situaciones en donde se dieran diferentes "realidades 
disonantes" (p. 28), en donde se hiciera patente la disonancia entre la cultura tradicional argelina y la cultura occidental (foto 2).

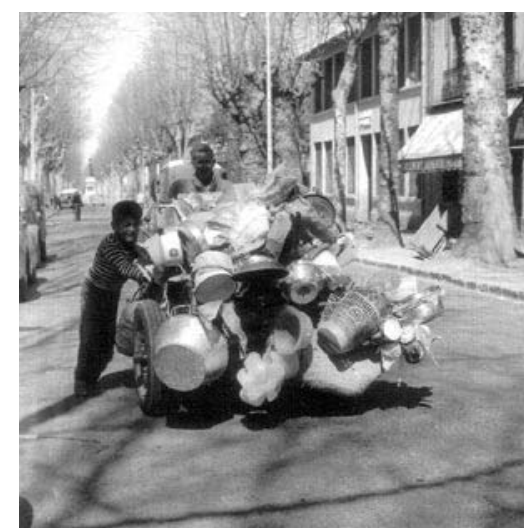

Foto 1: En: Bourdieu (2003, p. 164)

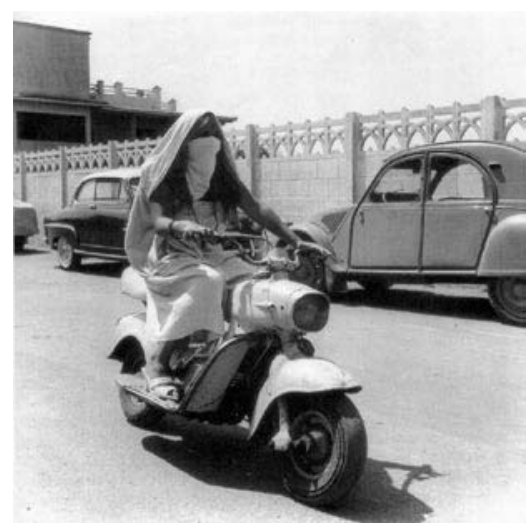

Foto 2: En: Bourdieu (2003, p. 47)

Se puede ver claramente que las fotos acompañaron las investigaciones y las reflexiones teóricas que Bourdieu desarrolló en Argelia. Muchas de las fotografías están destinadas a documentar los espacios, utensilios y ocupaciones de los argelinos. Más allá de una análisis del encuentro entre realidades disonantes estudió Bourdieu cómo la sociedad argelina iba poco a poco sucumbiendo ante la influencia de la política colonial y ante la propagación de la economía capitalista. Bourdieu analiza esta "conversión" de una sociedad tradicional a una sociedad capitalista no solamente estudiando el cambio del sistema económico, sino a la vez analizando cómo una economía dirigida a la prevención y al cálculo racional supuso una transformación de las formas de vida y de la mentalidad, es decir, del habitus de los argelinos. La producción fotográfica sirvió para captar los aspectos centrales del habitus de esta cultura en transformación en todos los campos posibles, desde la construcción de las viviendas a la organización del cementerio.

El concepto de habitus nos lleva otra vez a los historiadores del arte y en concreto al historiador Erwin Panofsky. En varios de sus escritos teóricos y metodológicos indica Bourdieu que el concepto 
central de su teoría, el concepto de habitus, proviene del historiador del arte Erwin Panofsky. Bourdieu se refiere concretamente al libro de Panofsky (1951) sobre la arquitectura y la escolástica en la edad media. En este estudio muestra Panofsky cómo el mismo habitus, la misma concepción del mundo del medioevo, se encuentra presente en el arte y en el pensamiento de la época. El concepto de habitus también fue utilizado por Mannheim (1923, p. 16) en el texto sobre el método de la interpretación documental. Es pues en esta tradición en la que la sociología de Bourdieu y en concreto sus investigaciones sobre Argelia han de ser enmarcados. Tanto la práctica fotográfica como las entrevistas y notas de observación participante le sirvieron a Bourdieu para analizar el habitus de la cultura argelina y su rápida transformación.

Hasta ahora no había sido presentado el análisis visual. La exposición sobre el material fotográfico de Bourdieu organizada por Camara Austria nos permite ver que la inclusión de la producción visual en estudios sociales puede servir como técnica de análisis y que también puede ser integrada en la presentación de los resultados de la investigación.

Para finalizar quiero señalar que en este tipo de utilización de la imagen como técnica para "retratar" una sociedad, las imágenes realizadas por el sociólogo pueden ser a su vez analizadas siguiendo el primer modelo de utilización del método de la interpretación documental, es decir, siguiendo el modelo que busca analizar la concepción del mundo del productor de imágenes. Las imágenes producidas por el investigador pueden ser analizadas como documentos de la concepción del mundo del sociólogo. Esta perspectiva le ofrece al sociólogo por un lado la posibilidad de autocrítica o de dar paso a un proceso de autoreflexión. Por otro lado se abre en esta autoreflexión un campo específico de trabajo, el de la sociología del conocimiento, es decir, el de una sociología del conocimiento sociológico. Karl Mannheim (1923, 1980a, 1980b) señaló en todos sus escritos metodológicos cómo toda interpretación documental hace patente la concepción del mundo del investigador. 
El investigador presta atención a diversos documentos y diversas características de un objeto de estudio y elige determinados enfoques y una determinada disposición de las fotos. En todas las elecciones del sociólogo podemos descubrir la perspectiva del análisis que éste ha elegido. Perspectiva que bien puede ser considerada como documento de una concepción del mundo.

\section{Conclusión}

Como ya señalé al comienzo, siguiendo los argumentos de Clarice Stasz (1979), la sociología como disciplina científica se vio obligada a limitar los métodos de estudio de la sociedad a análisis cuantitativos de lo social. En este proceso se separó la sociología de métodos como el análisis fotográfico, ensayístico y literario de la sociedad. Una sociología que se decida a utilizar la imagen no sólo como objeto de investigación, sino también como técnica de trabajo y de presentación de conocimiento, se verá obligada a reflexionar sobre las delimitaciones de la sociología como disciplina científica. Se verá en la situación de reconocer que las delimitaciones disciplinares no siempre ayudan a la hora de dar cuenta de su objeto de estudio. El análisis de una sociedad no es un campo privilegiado del sociólogo. También el cineasta, el fotógrafo, el artista o el escritor han dado con formas de presentación que muchas veces superan a los resultados de complicadas investigaciones sociológicas. El sociólogo que se proponga utilizar la imagen en sus estudios verá que los modelos para una sociología visual se encuentran muchas veces en estos campos fuera de la sociología como disciplina académica. La tarea del sociólogo que quiera utilizar medios visuales en sus investigaciones es hacer revivir esos aspectos que se fueron dejando de lado en la sociología.

Como hemos visto el método de interpretación documental no es sólo un método adecuado para un análisis sociológico de la imagen, sino que también es un método en donde la imagen en sí ofrece la técnica ideal de interpretación documental. Resumiendo: la 
imagen es para el método de interpretación documental tanto objeto de estudio como técnica de trabajo.

\section{Notas}

1 Este artículo es una versión de la conferencia "Sobre el uso de la imagen en la Sociología de la Cultura: el método de la interpretación documental del sociólogo Karl Mannheim", presentada el día 3 de julio de 2002 en el Congreso "Imagen: cultura y técnica" en la Universidad Carlos III de Madrid (Barboza 2005).

2 En el libro Kunst und Wissen: Die Stilanalyse in der Soziologie Karl Mannheim (Arte y Conocimiento: el análisis de estilo en la sociología de Karl Mannheim) he tratado justamente sobre la importancia de la recepción de los métodos de los historiadores del arte en la sociología de Mannheim. En este trabajo he reconstruido el método del análisis de estilos de arte, para después mostrar la manera en que Mannheim aplicó este método tanto en la sociología de la cultura como en la sociología del conocimiento.

3 Panofsky publicó la primera versión de su método de interpretación de obras de arte en 1932 en la revista Logos (n. 21, p. 103-119): "Das Problem der Beschreibung und Inhaltsdeutung von Werken der bildenden Kunst". Su reimpresión en la primera edición de los Studies in Iconology tuvo lugar en 1939, y la de Meaning in the Visual Arts data de 1957.

4 Me refiero a dos trabajos que Mannheim escribió en los años veinte y que permanecieron en forma de manuscrito hasta 1980, cuando fueron publicados por David Kettler, Volker Meja y Nico Stehr bajo el título "Estructuras del conocimiento" (Strukturen des Denkens). Estos dos manuscritos, "Sobre la particularidad del conocimiento de la sociología de la cultura" (Über die Eigenart kultursoziologischer Erkenntnis) y "Una teoría sociológica de la cultura y su conocimiento (pensamiento conjuntivo y comunicativo)" (Eine soziologische Theorie der Kultur und ihre Erkennbarkeit: Konjuktives und Kommunikatives Denken), han sido traducidos al inglés en: Karl Mannheim, Structures of Thinking, [David Kettler, Volker Meja y Nico Stehr (eds.)], Londres: Routledge and Kegan Paul, 1982. 
5 Este artículo, "Beiträge zur Theorie der WeltanschauungsInterpretation", fue publicado en 1923 en el anuario de la historia del arte, Jahrbuch für Kunstgeschichte. Este texto no ha sido traducido al español. En portugués ha sido publicado un artículo en donde se presenta el contenido de este texto (cf. Weller et al. 2002).

6 Panofsky publicó por primera vez su estudio "El desarrollo de la enseñanza de la proporción como muestra del desarrollo de estilo" (Die Entwicklung der Proportionslehre als Abbild der Stilentwicklung) en 1921 en Montashefte für Kunstwissenschaft, XIV, 1921, p. 188-219.

$7 \quad$ El análisis más conocido sobre los estilos de pensamiento se encuentra en el libro clásico de Mannheim, Ideología y Utopía, publicado por primera vez en 1929. En español existe una traducción del escrito original realizada por J. C. Gómez Muñoz en: Karl Mannheim, El problema de la sociología del saber, Madrid: Técnos, 1990. Mannheim realizó un análisis más exhaustivo sobre el estilo conservador en su Habilitación, que fue publica en una versión breve en 1927 (Versión española en: K. Mannheim, Ensayos sobre sociología y psicología social, México: Fondo de Cultura Económica, 1963, p. 84-183).

8 Sobre el proyecto del Atlas, cf. Gombrich (1992).

9 Estos ensayos - "Über Kunstausstellungen", "Zur Psychologie der Mode. Soziologische Studie", "Die Großstädte und das Geistesleben", "Die Bedutung des Geldes für das Tempo des Lebens"; "Der Bildrahmen. Ein ästhetischer Versuch" - se encuentran recopilados en Simmel (1998).

10 También en esta línea se encuentran la investigaciones de Richard Chalfen como "A sociovidistic approach to children's filmmaking: The Philadelphia Project" (1983) o la investigación "Picturing culture through indigenous imagery: a telling story" (1992).

11 De esta forma expone Susan Buck-Morss (1995, p. 45) el método de Walter Benjamin en el Proyecto de los Pasajes.

12 Para esta reconstrucción Susan Buck-Morss (1995, p. 15) se valió de la fotografía y del trabajo artístico de Michael Busch y Joan Sage, así como de el trabajo de cámara de Helen Kelley.

13 Muchas de las fotos están archivadas en: http://rs6.loc.gov/ammem/ fsowhome.html. 
14 Este trabajo de recuperación fue retomado por Camara Austria después de la muerte de Bourdieu. El libro Pierre Bourdieu: images d'Algérie, une affinité élective ha sido publicado en 2003 junto a la inauguración de una exposición en el Instituto del Mundo Árabe de Paris. Para más información: www.camera-austria.at.

On the method of documental interpretation and the use of images in Sociology: Kark Mannheim, Aby Warburg and Pierre Bourdieu

Abstract: The method of documental interpretation of the sociologist Karl Mannheim offers appropriate analysing tools to introduce visual data to sociological investigations. Because Mannheim had elaborated his methods based on the methodological progress of art historians. In the first part of this paper the central characteristics of this method will be presented. In the second part the author differences between two ways of application of this method in the way how to use visual data. On the one hand pictures could be objects of analysis of the method of documental interpretation, on the other hand they could also serve to make a documental analysis of the society.

Key-words: method of documental interpretation, Mannheim, visual data, Sociology, Warburg, Bourdieu.

\section{Bibliografía}

ADAIR, John; WORTH, Sol. Through Navajo eyes: an exploration in Film Communication and Anthropology. Bloomington/London: University Press, 1972.

BARBOZA, Amalia. Kunst und Wissen: Die Stilanalyse in der Soziologie Karl Mannheims. Konstanz: UVK Verlag, 2005.

Las imágenes como objeto y técnica de análisis en la sociología: el método de la interpretación documental. In: ROCHE CÁRCEL, Juan Antonio (Hg.). Encuentro entre Sociología y Antropología. Alicante: Editorial Universitat d'Alacant, 2005. p. 347-365.

. Die Eroberung des Formalen: Die Stilanalyse in der Kultur und Wissenssoziologie Karl Mannheims. 2002. Tesis doctoral, Technische Universität Dresden. 
BARBOZA, Amalia. Sobre el uso de la imagen en la sociología de la cultura. El método de la interpretación documental del sociólogo Karl Mannheim. In: AMADOR CARRETERO, Pilar; ROBLEDANO, Jesús; RUIZ FRANCO, Rosario (Ed.). Imagen, cultura y tecnología. Madrid: Universidad Carlos III, 2002. p. 201-213.

BOURDIEU, Pierre. Der Habitus als Vermittlung zwischen Struktur und Praxis. In: BOURDIEU. Soziologie der symbolischen Formen. Frankfurt a. M., 1974. p. 125-158. 2003.

In Algerien: Zeugnisse der Entwurzelung. Graz: Camera Austria,

BUCK-MORSS, Susan. Dialéctica de la mirada: Walter Benjamin y el Proyecto de los Pasajes. Madrid: Visor, 1995.

CESTELLI GUIDI, Benedetta; MANN, Nicholas (Ed.). Grenzerweiterungen: Aby Warburg in Amerika 1895-1896. Hambrug/ München: Dölling und Galitz Verlag, 1999.

CHALFEN, Richard. A sociovidistic approach to children's filmmaking: The Philadelphia Project. Studies in Visual Communication, p. 7084, 9 mar. 1983.

. Picturing culture through indigenous imagery: a telling story. In: CRAWFORD, Peter I.; TURTON, David. (Eds.). Film as Ethnography. Manchester: Manchester University Press, 1992. p. 222-241.

GOMBRICH, E. H. Aby Warburg. Madrid: Alianza, 1992.

MANNHEIM, Karl. Beiträge zur Theorie der Weltanschauungs-Interpretation. In: Kunstgeschichtliche Einzeldarstellungen. Wien: Hölzel, 1923.

. Eine soziologische Theorie der Kultur und ihrer Erkennbarkeit. In: MANNHEIM, Karl. Strukturen des Denkens. [David Kettler, Volker Meja, Nico Stehr (Ed.)]. Frankfurt a. M.: Suhrkamp, 1980a. p. 155-322.

. Über die Eigenart kultursoziologischer Erkenntnis. In: MANNHEIM, Karl. Strukturen des Denkens. [David Kettler, Volker Meja, Nico Stehr (Ed.)]. Frankfurt a. M.: Suhrkamp, 1980b. p. 33-154.

. Konservatismus: Ein Beitrag zur Soziologie des Wissens [David Kettler, Volker Meja, Nico Stehr (Ed.)]. Frankfurt a. M.: Suhrkamp, 1984. 
MANNHEIM, Karl. Ideologie und Utopie. Frankfurt a. M.: Vittorio Klostermann, 1995.

PANOFSKY, Erwin. Ikonographie und Ikonologie. In: PANOFSKY, E. Sinn und Deutung in der bildenden Kunst. Köln: Dumont, 1978. p. 36-67. (Edición castellana: El significado en las artes visuales. Buenos Aires: Infinito, 1970).

Die Perspektive als 'symbolische Form'. In: Aufsätze zu Grundfragen der Kunstwissenschaft. Berlin: Spiess, 1992a. p. 99-167. (Edición castellana: La perspectiva como forma simbólica. Barcelona: Tusquets, Cuadernos Marginales, 1973).

Zum Problem der Beschreibung und Inhaltsdeutung von Werken der bildenden Kunst. In: Aufsätze zu Grundfragen der Kunstwissenschaft. Berlin, Spiess, 1992b. p. 85-97. (Edición castellana: Estudios sobre iconología. Madrid: Alianza, 1972).

Die Entwicklung der Proportionslehre als Abbild der Stilentwicklung. In: Aufsätze zu Grundfragen der Kunstwissenschaft. Berlin, Spiess, 1992c. p. 169-204.

Gotische Architektur und Scholastik. Zur Analogie von Kunst, Philosophie und Theologie im Mittelalter. Köln, 1989. (Original en inglés: Gothic architecture and scholasticism, Pennsylvania, 1951).

RIEGL, Alois. Spätrömische Kunstindustrie. Darmstadt: Wissenschaftliche Buchgesellschaft, 1992.

SIMMEL, Georg. Philosophie des Geldes. Frankfurt a. Main: Suhrkamp, 1996.

. Soziologische Ästhetik. Bodenheim: Philo, 1998.

STASZ, Clarice. The Early History of Sociology. In: WAGNER, J. (Ed.). Images of information. Beverly Hills/London, 1979. p. 119-137.

WARBURG, Aby. Ausgewählte Schriften und Würdigungen. [Dieter Wuttke (Ed.)]. Baden-Baden: Valentin Koerner, 1992.

. Schlangenritual: Ein Reisebericht. Berlin: Wagenbach, 1988.

WELLER, Wivian et al. Karl Mannheim e o método documentário de interpretação: uma forma de análise das visões de mundo. Sociedade e Estado, Brasília, v. 17, n. 2, p. 375-396, 2002. 